\title{
PENGARUH BUDAYA ORGANISASI TERHADAP KINERJA KARYAWAN PADA PT XYZ
}

\section{Fitriana Dewi S, Astri Nur Rahmawati, Refani Khoirunnissa dan Ibnu Husni Fuadi}

Institut Manajemen Koperasi Indonesia

Email: fitrianads@gmail.com, astrinur1308@gmail.com, refanikhn@gmail.com dan Ibnuhuani123@gmail.com

\section{Abstract:}

Organizational culture is a characteristic or trait of an organization to become a reference in running the main objectives of the organization and to solve organizational problems. Organizational culture is needed to guide the behavior of employee's and improve employee's performance. This study aims to identify and analyze the influence of organizational culture on employees performance in PT Docotel Teknologi Bandung. The method used in this research is the descriptive and causal method with a quantitative approach. The sampling employed saturated sampling techniques that were all employees of PT Docotel Teknologi Bandung with a total of 40 peoples. Data were analyzed using descriptive analysis and simple linear regression analysis. The results of this study indicates that organizational culture has a positive influence on employee performance and has a relationship level of 0.395 or $39.5 \%$, which states that the relationship between the two variables is low. So that the independent organizational culture has an effect of $15.6 \%$ on the employee performance, while the remaining $84.4 \%$ is influenced by other factors not examined in this study. Employees are expected to follow organizational culture optimally, especially on agreements to apply existing values and rules to improve performance

Keywords: organizational culture; employees ; performance

\section{Abstrak}

Budaya organisasi merupakan karakteristik atau ciri suatu organisasi untuk menjadi referensi dalam menjalankan tujuan utama organisasi dan untuk menyelesaikan masalah organisasi. Budaya organisasi diperlukan untuk memandu perilaku karyawan dan meningkatkan kinerja karyawan. Penelitian ini bertujuan untuk mengetahui dan menganalisis Pengaruh Budaya Organisasi Terhadap Kinerja Karwawan Pada PT XYZ. Metode yang digunakan dalam penelitian ini adalah metode deskriptif dan kausal dengan pendekatan kuantitatif. Pengambilan sampel menggunakan teknik sampling jenuh yaitu seluruh karyawan PT XYZ yang berjumlah 40 orang. Teknik analisis data menggunakan analisis deskriptif dan analisis regresi linear sederhana. Hasil Penelitian ini menunjukkan bahwa Budaya Organisasi memiliki pengaruh positif terhadap Kinerja Karyawan dan mempunyai tingkat keeratan hubungan sebesar 0,395 atau 39,5\%, yang menyatakan bahwa

$\begin{array}{ll}\text { How to cite: } & \text { S, Fitriana Dewi,. et. al (2021). Pengaruh Budaya Organisasi terhadap Kinerja Karyawan pada PT } \\ & \text { XYZ. Syntax Literate: Jurnal Ilmiah Indonesia. } 6(4) . \text { http://10.36418/syntax-literate.v6i4.1027 } \\ \text { E-ISSN: } & \text { 2548-1398 } \\ \text { Published by: } & \text { Ridwan Institute }\end{array}$


hubungan kedua variabel adalah rendah. Sehingga Budaya Organisasi memiliki pengaruh sebesar $15,6 \%$ terhadap Kinerja Karyawan, sedangkan sisanya sebesar $84,4 \%$ dipengaruhi oleh faktor lain yang tidak diteliti dalam penelitian ini. Karyawan diharapkan mampu mengikuti budaya organisasi secara maksimal terutama pada kesepakatan untuk melaksanakan nilai-nilai dan aturan yang ada sehingga dapat meningkatkan kinerja.

Kata Kunci: budaya organisasi; karyawan; kinerja.

\section{Pendahuluan}

Tangga kehidupan membawa suatu keadaan tahap tingkatan perkembangan dari berbagai bidang. Perkembangan teknologi yang sering menjadi tantangan bagi suatu negara, mengharuskan negara tersebut beradaptasi dengan perkembangan ini. Teknologi mengacu pada obyek benda yang digunakan untuk kemudahan aktivitas manusia, seperti mesin, perkakas, atau perangkat keras. Perkembangan teknologi ini memunculkan suatu keadaan dimana aktivitas manusia akan lebih mudah dan cepat. Hal ini terlihat peran kualitas Sumber Daya Manusia (SDM) dalam suatu negara akan sangat dibutuhkan.

Perkembangan teknologi di Indonesia yang terus berkembang disegala bidang dibantu dengan tangan ahli dibidang teknologi. Kondisi ini melahirkan peluang bisnis bahkan peluang kerja yang sangat besar bagi orang-orang yang mengerti bidang teknologi khususnya. Peluang bisnis yang dimaksudkan dimana suatu organisasi yang bergerak dibidang teknologi untuk memberikan jasa teknologi informasi yang dulunya sangat jarang ditemukan, seiring berjalannya waktu sangat banyak organisasi yang berdiri dan bergerak dibidang teknologi informasi. Hal ini memunculkan persaingan yang ketat antar organisasi teknologi informasi, persaingan ini timbul karena kebutuhan teknologi yang canggih dan aman sehingga para konsumen/pelanggan/klien pasti akan mencari perusahaan yang akan memberikan kinerja terbaik.

Menurut (Sutarto, 2015) menjelaskan bahwa kondisi yang terjadi dalam bidang organisasi antara lain terdapat masalah karyawannya banyak yang tidak mengetahui apalagi meyakini tujuan organisasi tempatnya bekerja, adanya pembentukan organisasi yang didasarkan atas faktor lain di luar administrasi, seperti faktor politik, sosial dan lain-lain, karyawan tidak memiliki rincian tugas yang jelas yang dapat dijadikan acuan untuk mengetahui apa yang menjadi tanggung jawabnya, sehingga banyak yang bekerja hanya menunggu perintah dari atasan, pelayanan terhadap masyarakat terkadang terhambat karena petugasnya sedang berhalangan, adanya kesamaan pengerjaan atau sebaliknya kekosongan pengerjaan atas sesuatu aktivitas karena adanya satuan-satuan organisasi atau jabatan-jabatan sama, kurang menyadari bahwa setiap pejabat seharusnya melaksanakan tugas tanpa menunggu atasannya, adanya penempatan suatu organisasi yang belum tepat dan adanya pembangunan organisasi yang rumit.

Kemunculan persaingan dari pihak eksternal dan permasalahan dari pihak internal mengharuskan suatu perusahaan dapat membentuk karakter atau sifat yang kuat untuk menjadi senjata dalam persaingan dengan organisasi lain. Karakter atau sifat ini 
sering kita kenal dengan Budaya organisasi. Menurut (Robbins, 2015) pengertian budaya organisasi adalah sistem makna bersama yang dianut oleh anggota-anggota yang membedakan suatu organisasi dari organisasi lain. Sistem makna bersama ini, bila diamati dengan lebih seksama, merupakan seperangkat karakteristik utama yang dihargai oleh suatu organisasi. Adapun Menurut (Badeni, 2013) menjelaskan bahwa budaya organisasi merupakan seperangkat nilai, asumsi-asumsi, dan standar perilaku yang berkembang dan diyakini oleh sebagian besar anggota organisasi sebagai acuan dalam menjalankan organisasi atau memecahkan permasalahan organisasi, baik secara internal (peningkatan efektivitas, efisiensi, dan integritas) maupun menghadapi masalah-masalah eksternal. Sedangkan menurut (Erni, 2011) bahwa budaya organisasi merupakan gaya dan cara hidup dari suatu organisasi yang merupakan pencerminan dari nilai-nilai atau kepercayaan yang selama ini dianut oleh seluruh anggota organisasi. Sebuah organisasi mempunyai budaya masing-masing, hal ini menjadi salah satu pembeda antara satu organisasi dengan organisasi lainnya. Budaya sebuah organisasi bisa saja mempengaruhi kinerja karyawan pada orgaisasi tersebut.

Menurut (Anwar Prabu, 2012), kinerja (prestasi kerja) adalah hasil kerja secara kualitas dan kuantitas yang dicapai oleh seorang pegawai dalam melaksanakan tugasnya sesuai dengan tanggung jawab yang diberikan kepadanya. Menurut (Wirawan, 2015) kinerja adalah keluaran yang dihasilkan oleh fungsi-fungsi atau indikatorindikator suatu pekerjaan atau suatu profesi dalam waktu tertentu. Menurut (Wilson, 2012) menjelaskan bahwa kinerja adalah hasil pekerjaan yang dicapai seseorang berdasarkan persyaratanpersyartan pekerjaan. Apabila kinerja karyawan dalam suatu perusahaan tidak ditata dengan baik maka akan dapat menjadi salah satu penghambat aktivitas perusahaan dalam mencapai tujuannya. Penataan kinerja ini tentunya juga memerlukan penyesuaian kondisi atau keadaan perusahaan agar sanggup bersaing dengan perusahaan lain dalam era globalisasi saat ini. Menurut (Torang, 2013) menjelaskan bahwa kinerja merupakan kuantitas dan kualitas hasil kerja individu atau sekelompok individu dalam organisasi untuk melaksanakan tugas pokok dan fungsi yang berpedoman pada norma, standar operasional prosedur, kriteria dan ukuran yang telah ditetapkan atau yang berlaku dalam organisasi. Menurut (Sedarmayanti, 2017) kinerja karyawan merupakan terjemahan dari performance yang berarti hasil kerja seorang pekerja, sebuah proses manajemen atau suatu organisasi secara keseluruhan, dimana hasil kerja tersebut harus dapat ditunjukkan buktinya secara konkrit dan dapat diukur (dibandingkan dengan standar yang telah ditentukan). Menurut (Edison, Anwar, \& Komariyah, 2016) dalam (Amanda, Budiwibowo, \& Amah, 2017) menjelaskan beberapa indikator untuk mengukur kinerja yaitu meliputi target, kualitas, waktu penyelesaian suatu pekerjaan, dan taat asas.

Hubungan budaya organisasi dengan kinerja menurut Menurut Kotter \& Haskett dalam (Sudarmanto, 2014) logika tentang cara kekuatan budaya itu berhubungan dengan kinerja meliputi tiga gagasan, yaitu penyatuan tujuan, membantu kinerja bisnis karena menciptakan suatu tingkat motivasi yang luar biasa dalam diri para karyawan, dan memberikan struktur dan kontrol yang dibutuhkan tanpa harus bersandar pada birokrasi formal yang mencekik yang dapat menekan tumbuhnya motivasi dan inovasi. 
Menurut (Wardani, Mukzam, \& Mayowan, 2016) hubungan antara budaya organisasi dengan kinerja karyawan dapat tercermin dalam perilaku organisasi tersebut, sebagai contoh karyawan meniru perilaku yang sesusai dengan budaya organisasinya maka akan ada kepuasan tersendiri dan bahkan ada imbalan secara langsung atau tidak langsung. Budaya organisasi menjadi suatu pedoman perilaku bagi anggotanya yang secara tidak sadar diterapkan dalam menjalankan kegiatannya.

Adapun beberapa penelitian terdahulu yang menjadi pendukung melakukan penelitian ini yaiut menurut penelitian (Novziransyah, 2017) bahwa budaya organisasi memiliki pengaruh yang signifikan terhadap kinerja karyawan PT. PLN (Persero) Kantor Wilayah Sumatera Utara Medan. Adapun hasil penelitian menurut (Sagita, dkk, 2018) menunjukkan bahwa budaya organisasi memiliki nilai signifikan terhadap kinerja karyawan pada PT Astra Internasional. Penelitian (Lathifah, dkk., 2015) hasil penelitiannya juga menunjukan bahwa budaya organisasi berpengaruh signifikan terhadap kinerja karyawan Madrasah Aliyah Negeri (MAN) Cimahi.

PT XYZ merupakan salah satu perusahaan yang bergerak dibidang pemberian jasa mengenai Information Technology (IT). Dimana sebuah tim yang terdiri dari orangorang kreatif dan inovatif yang berdedikasi untuk menyediakan layanan Information Technology (IT) berkualitas tinggi yang dipadukan dengan intergritas dan diposisi ramah. Berbagai layanan kami termasuk pengembangan Aplikasi Web \& Aplikasi Seluler, Pemasaran Digital \& Sistem Intergrator (SI). Dalam rangka meningkatkan kinerja pegawai yang berkualitas dan professional salah satu faktor yang cocok untuk diterapkan dalam lingkungan kerja ialah budaya organisasi. Budaya organisasi dapat menciptakan kinerja yang baik, karena PT XYZ tidak ingin ketinggalan dalam membangun budaya organisasi yang efektif guna menciptakan kinerja karyawan yang baik.

Dalam penelitian ini ditemukan beberapa masalah berdasarkan hasil wawancara yang dilakukan oleh peneliti, yaitu (1) beberapa pegawai masih ada yang terlambat datang kerja, (2) beberapa pegawai masih ada yang meninggal pekerjaan untuk urusan pribadi, (3) Beberapa pegawai masih ada yang sulit untuk beradaptasi dengan pekerjaannya. Dengan masalah ini peneliti bertujuan untuk mengetahui Pengaruh Budaya Organisasi (organization culture) Terhadap Kinerja Karyawan Pada PT XYZ.

Mengingat variabel bebas dalam penelitian ini merupakan hal yang baik dalam mempengaruhi kinerja karyawan diharapkan hasil penelitian ini dapat dipakai sebagai acuan bagi peneliti selanjutnya untuk mengembangkan penelitian ini dengan mempertimbangkan variabel- variabel selain yang digunakan dalam penelitian ini.

Hasil penelitian ini nantinya dapat memberikan manfaat bagi PT. XYZ dalam hal meningkatkan kualitas Sumber Daya Manusia (SDM) karyawannya dan dalam hal pengembangan ilmu pengetahuan. Adapun tujuan dari penelitian ini adalah untuk mengetahui pengaruh budaya organisasi terhadap kinerja karyawan pada PT.XYZ. 


\section{Metode Penelitian}

Penelitian tentang Pengaruh Budaya Organisasi Terhadap Kinerja Karyawan PT XYZ menggunakan metode kuantitatif yang digunakan adalah metode survei, yang bersifat deskriptif dan asosiatif hubungan kausal. Menurut (Sugiyono, 2017) metode survei merupakan salah satu metode kuantitatif adalah Metode penelitian survei adalah metode penelitian kuantitatif yang digunakan untuk mendapatkan data yang terjadi pada masa lampau atau saat ini, tentang keyakinan, pendapat, karakteristik, perilaku, hubungan variabel dan untuk menguji beberapa hipotesis tentang variabel sosiologis dan psikologis dari sampel yang diambil dari populasi tertentu, teknik pengumpulan data dengan pengamatan (wawancara atau kuesioner) yang tidak mendalam, dan hasil penelitian cenderung untuk digeneralisasikan. Subjek Penelitian yaitu seluruh karyawan PT XYZ dengan jumlah karyawan sebanyak 40 orang, dikarenakan jumlah karyawan kurang dari 100 orang maka kita menguji dengan populasinya.

Penelitian ini bertujuan untuk mengetahui hubungan antara dua variabel yaitu Variabel independen (variabel bebas) atau variabel (X) adalah Budaya Organisasi dan Variabel dependen (variabel tidak bebas) atau variabel (Y) adalah Kinerja Karyawan. Teknik pengumpulan data dalam penelitian ini menggunakan data kuesioner dengan teknik pengukuran data kami menggunakan skala likert. Dengan skala likert responden memilih jawaban dari variabel yang dipecah menjadi bagian dari indikator variabel, masing-masing indikator variabel mempunyai instrumen yang dijadikan tolak ukur dalam sebuah pertanyaan atau pernyataan. Teknik analisis data menggunakan beberapa metode analisis yaitu Analisis Deskriptif, Uji Validitas dan Reliabilitas, dan Analisis Regresi Sederhana yang mencakup Uji Normalitas, Uji heteroskedastisitas, Uji Regresi Linear Sederhana, Uji Hipotesis (Uji t), dan Koefisien Determinasi.

\section{Hasil dan Pembahasan}

\section{A. Hasil penelitian}

\section{Analisis deskriptif}

Berdasarkan pengujian dengan menggunakan analisis deskriptif ini dari variabel Budaya Organisasi (X) dari 40 responden yang dijadikan sampel, dapat diketahui hasil pengujian dari seluruh indikator budaya organisasi memperoleh total score 165 maka dapat dinilai Setuju. Sedangkan untuk variabel Kinerja Karyawan (Y) dari 40 responden yang dijadikan sampel, dapat diketahui hasil pengujian dari seluruh indikator kinerja karyawan memperoleh total score 168 maka dapat dinilai Sangat Setuju.

\section{Uji validitas dan reliabilitas}

\subsection{Variabel budaya organisasi $(x)$}

2.1.1. Uji Validitas

Data dapat dikatakan Valid jika :

a. Membandingkan Nilai $R_{\text {hitung }}$ dengan Nilai $\mathbf{R}_{\text {tabel }}$

Nilai Tabel R : perbandingan df ; $\alpha=(40-2) ; 0,05=0,3120$

- Jika nilai $\mathrm{R}_{\text {hitung }}>\mathrm{R}_{\text {hitung }}$ maka dinyatakan Valid 
Fitriana Dewi S, Astri Nur Rahmawati, Refani Khoirunnissa dan Ibnu Husni Fuadi

- Jika nilai $\mathrm{R}_{\text {hitung }}<\mathrm{R}_{\text {hitung }}$ maka dinyatakan Tidak Valid

b. Membandingkan Nilai $\mathrm{R}_{\text {hitung }}$ dengan Nilai P-Level/Sig.(2-tailed)

- Jika nilai Sig.(2-tailed) $<0,05$ dan Pearson Correlation bernilai Positif, maka dinyatakan Valid

- Jika nilai Sig.(2-tailed) < 0,05 dan Pearson Correlation bernilai Negatif, maka dinyatakan Tidak Valid

- Jika nilai Sig.(2-tailed) > 0,05 dan Pearson Correlation bernilai, maka dinyatakan Tidak Valid.

Berdasarkan hasil pengujian uji validitas untuk variabel Budaya Organisasi di peroleh sebagai berikut:

\section{Tabel 1}

Hasil Uji Validasi Variabel Budaya Organisasi (X)

\begin{tabular}{llll}
\hline Keterangan & Pearson Correlation & Sig.(2-tailed) & Simpulan \\
\hline Indikator 1 & 0,575 & 0,000 & Valid \\
\hline Indikator 2 & 0,323 & 0,042 & Valid \\
\hline Indikator 3 & 0,530 & 0,000 & Valid \\
\hline Indikator 4 & 0,471 & 0,002 & Valid \\
\hline Indikator 5 & 0,369 & 0,019 & Valid \\
\hline Indikator 6 & 0,577 & 0,000 & Valid \\
\hline Indikator 7 & 0,391 & 0,012 & Valid \\
\hline Indikator 8 & 0,559 & 0,000 & Valid \\
\hline Indikator 9 & 0,766 & 0,000 & Valid \\
\hline Indikator 10 & 0,564 & 0,000 & Valid \\
\hline Indikator 11 & 0,754 & 0,000 & Valid \\
\hline Indikator 12 & 0,575 & 0,000 & Valid \\
\hline Indikator 13 & 0,611 & 0,000 & Valid \\
\hline Indikator 14 & 0,597 & 0,000 & Valid \\
\hline Indikator 15 & 0,629 & 0,000 & Valid \\
\hline Indikator 16 & 0,526 & 0,000 & Valid \\
\hline Indikator 17 & 0,465 & 0,003 & Valid \\
\hline Indikator 18 & 0,644 & 0,000 & Valid \\
\hline Indikator 19 & 0,552 & 0,000 & Valid \\
\hline Indikator 20 & 0,733 & 0,000 & Valid
\end{tabular}

Berdasarkan Tabel 1 maka dapat dilihat bahwa seluruh pernyataan atau indikator untuk variabel Budaya Organisasi dinyatakan Valid, karena nilai Pearson Correlation lebih besar dari Sig.(2-tailed).

$$
\mathrm{P}=\left(\frac{20}{20} \mathrm{X} 100 \%\right)=100 \%
$$

Jadi, dapat disimpulkan bahwa variabel Budaya Organisasi dinyatakan Valid atau layak dengan probability $100 \%$.

2.1.2. Uji Reliabilitas

Data dapat dikatakan reliabel jika : 
a. Membandingkan Nilai cronbach's alpha dengan Nilai $\mathrm{R}_{\text {tabel }}$ Nilai Tabel R : perbandingan df; $\alpha=(40-2) ; 0,05=0,3120$

- Jika nilai cronbach's alpha $>\mathrm{R}_{\text {tabel }}$ maka dinyatakan Reliabel.

- Jika nilai cronbach's alpha $<\mathrm{R}_{\text {tabel }}$ maka dinyatakan Tidak Reliabel.

Berdasarkan hasil pengujian uji reliabilitas untuk variabel Budaya Organisasi di peroleh sebagai berikut:

Tabel 2

Hasil Uji Reliabilitas Variabel Budaya Organisasi (X)

\begin{tabular}{llll}
\hline Keterangan & Cronbach's Alpha & R tabel & Simpulan \\
\hline Indikator 1 & 0,878 & 0,3120 & Reliabel \\
\hline Indikator 2 & 0,886 & 0,3120 & Reliabel \\
\hline Indikator 3 & 0,879 & 0,3120 & Reliabel \\
\hline Indikator 4 & 0,881 & 0,3120 & Reliabel \\
\hline Indikator 5 & 0,886 & 0,3120 & Reliabel \\
\hline Indikator 6 & 0,878 & 0,3120 & Reliabel \\
\hline Indikator 7 & 0,884 & 0,3120 & Reliabel \\
\hline Indikator 8 & 0,879 & 0,3120 & Reliabel \\
\hline Indikator 9 & 0,872 & 0,3120 & Reliabel \\
\hline Indikator 10 & 0,880 & 0,3120 & Reliabel \\
\hline Indikator 11 & 0,871 & 0,3120 & Reliabel \\
\hline Indikator 12 & 0,878 & 0,3120 & Reliabel \\
\hline Indikator 13 & 0,877 & 0,3120 & Reliabel \\
\hline Indikator 14 & 0,877 & 0,3120 & Reliabel \\
\hline Indikator 15 & 0,876 & 0,3120 & Reliabel \\
\hline Indikator 16 & 0,879 & 0,3120 & Reliabel \\
\hline Indikator 17 & 0,882 & 0,3120 & Reliabel \\
\hline Indikator 18 & 0,876 & 0,3120 & Reliabel \\
\hline Indikator 19 & 0,879 & 0,3120 & Reliabel \\
\hline Indikator 20 & 0,872 & 0,3120 & Reliabel \\
\hline
\end{tabular}

Berdasarkan Tabel 2 uji reliabilitas untuk seluruh pernyataan atau indikator untuk variabel Budaya Organisasi menyatakan Reliabel, karena nilai cronbach's alpha lebih besar dari $\mathrm{R}_{\text {tabel }} 0,3120$.

Tabel 3

.Hasil Uji Reliabilitas Keseluruhan Variabel Budaya Organisasi (X) Reliability Statistics

\begin{tabular}{c|c}
\hline Cronbach's Alpha & N of Items \\
\hline, 884 & 20 \\
\hline
\end{tabular}

Berdasarkan Tabel 3 hasil uji reliabilitas untuk variabel Budaya Organisasi menyatakan Reliabel, karena nilai cronbach's alpha sebesar 0,884 lebih besar dari $\mathrm{R}_{\text {tabel }} 0,3120$. 


\subsection{Variabel kinerja karyawan (y)}

\subsubsection{Uji Validitas}

Data dapat dikatakan Valid jika :

c. Membandingkan Nilai $R_{\text {hitung }}$ dengan Nilai $R_{\text {tabel }}$

Nilai Tabel R : perbandingan df ; $\alpha=(40-2) ; 0,05=0,3120$

- Jika nilai $\mathrm{R}_{\text {hitung }}>\mathrm{R}_{\text {hitung }}$ maka dinyatakan Valid

- Jika nilai $\mathrm{R}_{\text {hitung }}<\mathrm{R}_{\text {hitung }}$ maka dinyatakan Tidak Valid

d. Membandingkan Nilai $R_{\text {hitung }}$ dengan Nilai P-Level/Sig.(2-tailed)

- Jika nilai Sig.(2-tailed) $<0,05$ dan Pearson Correlation bernilai Positif, maka dinyatakan Valid

- Jika nilai Sig.(2-tailed) $<0,05$ dan Pearson Correlation bernilai Negatif, maka dinyatakan Tidak Valid

- Jika nilai Sig.(2-tailed) > 0,05 dan Pearson Correlation bernilai, maka dinyatakan Tidak Valid.

Berdasarkan hasil pengujian uji validitas untuk variabel Budaya Organisasi di peroleh sebagai berikut:

Tabel 4

Hasil Uji Validasi Variabel Kinerja Karyawan (Y)

\begin{tabular}{llll}
\hline Keterangan & Pearson Correlation & Sig.(2-tailed) & Simpulan \\
\hline Indikator 1 & 0,506 & 0,001 & Valid \\
\hline Indikator 2 & 0,622 & 0,000 & Valid \\
\hline Indikator 3 & 0,424 & 0,006 & Valid \\
\hline Indikator 4 & 0,320 & 0,044 & Valid \\
\hline Indikator 5 & 0,588 & 0,000 & Valid \\
\hline Indikator 6 & 0,666 & 0,000 & Valid \\
\hline Indikator 7 & 0,751 & 0,000 & Valid \\
\hline Indikator 8 & 0,645 & 0,000 & Valid \\
\hline Indikator 9 & 0,662 & 0,000 & Valid \\
\hline Indikator 10 & 0,608 & 0,000 & Valid \\
\hline
\end{tabular}

Berdasarkan Tabel 4 maka dapat dilihat bahwa seluruh pernyataan atau indikator untuk variabel Kinerja Karyawan dinyatakan Valid, karena nilai Pearson Correlation lebih besar dari Sig.(2-tailed).

$$
\mathrm{P}=\left(\frac{10}{10} \mathrm{X} 100 \%\right)=100 \%
$$

Jadi, dapat disimpulkan bahwa variabel Kinerja Karyawan dinyatakan Valid atau layak dengan probability $100 \%$.

2.2.2. Uji Reliabilitas

Data dapat dikatakan reliabel jika :

a. Membandingkan Nilai cronbach's alpha dengan Nilai $\mathbf{R}_{\text {tabel }}$ Nilai Tabel R : perbandingan df ; $\alpha=(40-2) ; 0,05=0,3120$

- Jika nilai cronbach's alpha $>\mathrm{R}_{\text {tabel }}$ maka dinyatakan Reliabel. 


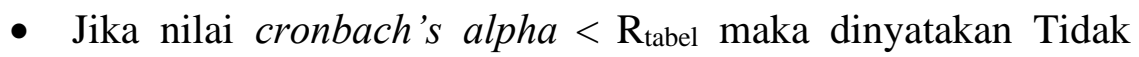
Reliabel.

Berdasarkan hasil pengujian uji reliabilitas untuk variabel Budaya Organisasi di peroleh sebagai berikut:

Tabel 5

Hasil Uji Reliabilitas Variabel Kinerja Karyawan (Y)

\begin{tabular}{llll}
\hline Keterangan & Cronbach's Alpha & R tabel & Simpulan \\
\hline Indikator 1 & 0,762 & 0,3120 & Reliabel \\
\hline Indikator 2 & 0,749 & 0,3120 & Reliabel \\
\hline Indikator 3 & 0,779 & 0,3120 & Reliabel \\
\hline Indikator 4 & 0,790 & 0,3120 & Reliabel \\
\hline Indikator 5 & 0,757 & 0,3120 & Reliabel \\
\hline Indikator 6 & 0,741 & 0,3120 & Reliabel \\
\hline Indikator 7 & 0,724 & 0,3120 & Reliabel \\
\hline Indikator 8 & 0,744 & 0,3120 & Reliabel \\
\hline Indikator 9 & 0,741 & 0,3120 & Reliabel \\
\hline Indikator 10 & 0,748 & 0,3120 & Reliabel \\
\hline
\end{tabular}

Berdasarkan Tabel 5 uji reliabilitas untuk seluruh pernyataan atau indikator untuk variabel Kinerja Karyawan menyatakan Reliabel, karena nilai cronbach's alpha lebih besar dari $\mathrm{R}_{\text {tabel }} 0,3120$.

Tabel 6

Hasil Uji Reliabilitas Keseluruhan Variabel Kinerja Karyawan (Y) Reliability Statistics

\begin{tabular}{cc}
\hline $\begin{array}{c}\text { Cronbach's } \\
\text { Alpha }\end{array}$ & $\mathrm{N}$ of Items \\
\hline, 773 & 10 \\
\hline
\end{tabular}

Berdasarkan Tabel 6 hasil uji reliabilitas untuk variabel Kinerja Karyawan menyatakan Reliabel, karena nilai cronbach's alpha sebesar 0,773 lebih besar dari $\mathrm{R}_{\text {tabel }} 0,3120$.

\section{Analisis regresi sederhana}

\subsection{Uji normalitas}

Uji normalitas merupakan alat diagnostik yang digunakan untuk menjelaskan normalitas data. Uji ini dilakukan dengan menggunakan teknik Kolmogorov-Smirnov. Suatu data dapat dikatakan normal jika nilai signifikansi lebih dari (>) 0,05 atau hipotesis penelitian yang diterima adalah $\mathrm{H}_{0}$.

Selain itu normalitas data dapat dilihat pada grafik Normal P-P PLOT dan histogram yang menunjukkan suatu distribusi data. Distribusi data pada histogram data dapat dikatakan berdistribusi normal ketika sebaran data (histogram) mengikuti bentuk kurva normal yang berbentuk seperti lonceng. Dan pada grafik Normal P-P Plot dapat dikatakan berdistribusi normal jika plot data menyebar mendekati garis diagonal dan mengikuti alur ke kanan atas.

Hipotesis : Uji Normalitas 
Fitriana Dewi S, Astri Nur Rahmawati, Refani Khoirunnissa dan Ibnu Husni Fuadi

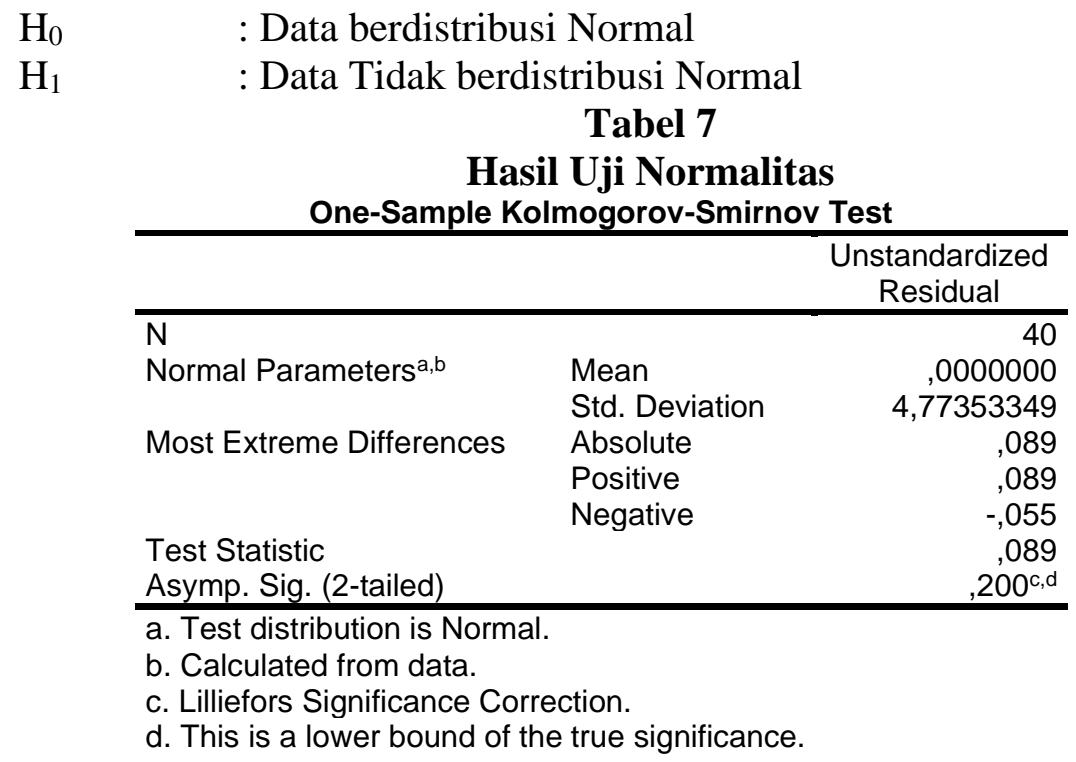

a Karyawan (Y) dengan uji Kolmogorov-Smirnov pada tingkat kepercayaan 95\% diperoleh signifikansi sebesar 0,200 yang berarti lebih besar dari 0,05, artinya hipotesis yang diterima adalah $\mathrm{H}_{0}$ atau dapat dikatakan data berdistribusi normal.

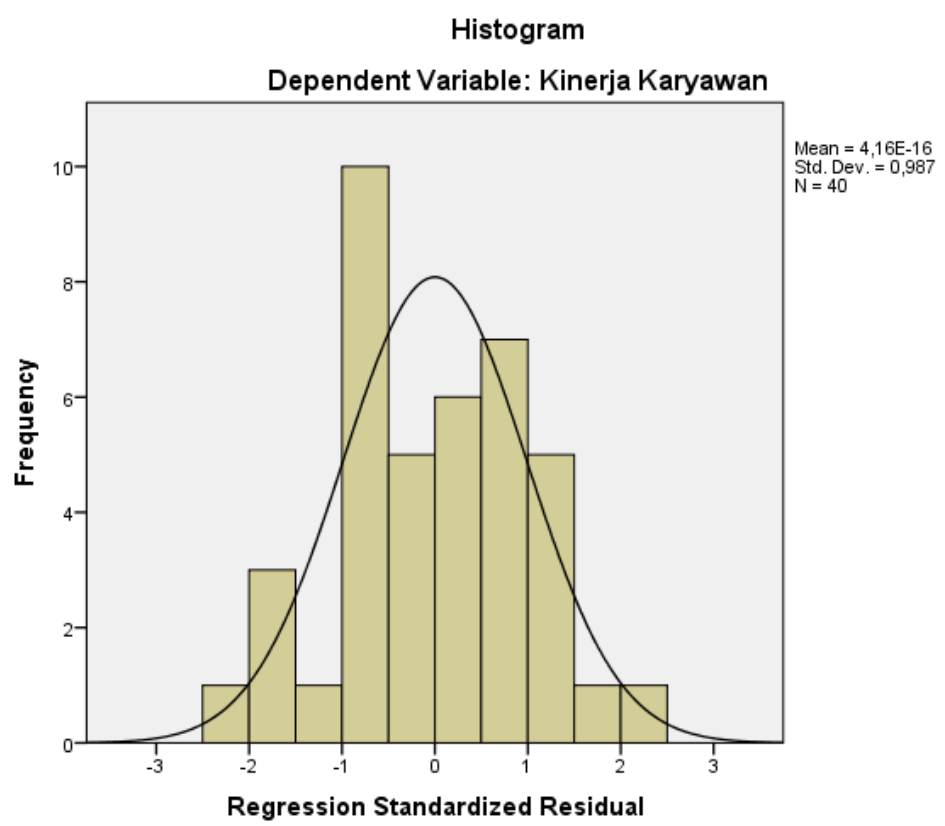

\section{Gambar 1 \\ Histogram}

Berdasarkan gambar diatas dapat dilihat bahwa histogram cenderung membentuk kurva normal. 


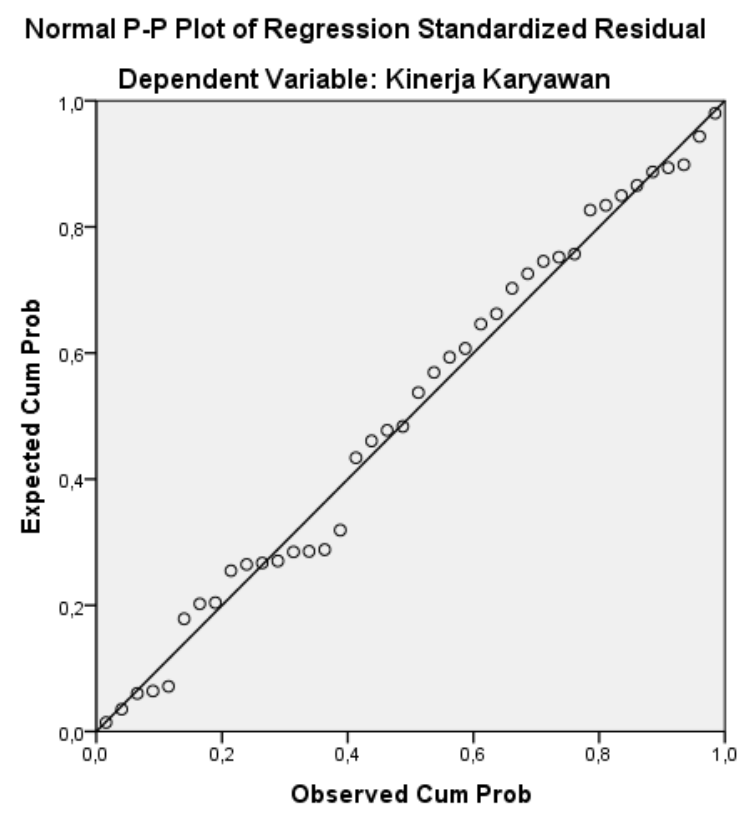

Gambar 2

\section{Normal P-P Plot}

Berdasarkan gambar diatas dapat dilihat bahwa Normal P-P Plot menunjukkan data menyebar disekitar garis diagonal dan mengikuti arah garis diagonal, maka model regresi memenuhi asumsi normalitas.

Jadi, dari beberapa hasil pengujian normalitas dapat disimpulkan bahwa data tersebut berdistribusi normal.

\subsection{Uji heteroskedastisitas}

Heteroskedastisitas merupakan salah satu faktor yang menyebabkan model regresi linier tidak efisien dan akurat, juga mengakibatkan penggunaan metode kemungkinan maksimum dalam mengestimasi parameter (koefisien) regresi akan terganggu.

Uji Glejser dilakukan dengan cara meregresikan antara variabel independen dengan nilai absolut residualnya. Jika nilai signifikansi antara variabel independen dengan absolut residual lebih dari 0,05 maka tidak terjadi masalah heteroskedastisitas.

Tabel 8

Hasil Pengujian Asumsi Heteroskedastisitas (Uji Glejser) Coefficients $^{a}$

\begin{tabular}{|c|c|c|c|c|c|c|}
\hline \multirow[b]{2}{*}{ Model } & & Unstandardize & Coefficients & $\begin{array}{c}\text { Standardized } \\
\text { Coefficients }\end{array}$ & \multirow[b]{2}{*}{$\mathrm{t}$} & \multirow[b]{2}{*}{ Sig. } \\
\hline & & $\mathrm{B}$ & Std. Error & Beta & & \\
\hline \multirow[t]{2}{*}{1} & (Constant) & 2,367 & 2,547 & & ,929 & ,359 \\
\hline & Budaya Organisasi & ,026 & ,043 & ,099 & 614 & ,543 \\
\hline
\end{tabular}

a. Dependent Variable: ABS_Res 
Berdasarkan tabel coefficients diatas diperoleh nilai signifikansi untuk variabel Budaya Organisasi sebesar 0.543 dan nilai variabel bebas tersebut lebih besar dari 0,05 yang artinya tidak terjadi masalah heteroskedastisitas.

\subsection{Regresi linear sederhana}

Analisis regresi ini digunakan untuk melihat pengaruh antara variabel $\mathrm{X}$ terhadap variabel Y secara parsial.

Tabel 9

Nilai Koefisien Regresi Budaya Organisasi (X) Terhadap Kinerja

Karyawan (Y)

Coefficients $^{\mathrm{a}}$

\begin{tabular}{|c|c|c|c|c|c|c|}
\hline \multirow[b]{2}{*}{ Model } & & \multicolumn{2}{|c|}{ Unstandardized Coefficients } & $\begin{array}{l}\text { Standardized } \\
\text { Coefficients }\end{array}$ & \multirow[b]{2}{*}{$\mathrm{t}$} & \multirow[b]{2}{*}{ Sig. } \\
\hline & & $\mathrm{B}$ & Std. Error & Beta & & \\
\hline 1 & (Constant) & 18,552 & 4,581 & & 4,049 &, 000 \\
\hline & Budaya Organisasi & 203 & ,077 & ,395 & 2,649 & ,012 \\
\hline
\end{tabular}

a. Dependent Variable: Kinerja Karyawan

Berdasarkan hasil pada tabel coefficients diatas, regresi linier sederhana diperoleh nilai koefisien regresi untuk variabel Budaya Organisasi (X) sebesar 0,203 , dengan nilai konstanta sebesar 18,552. Sehingga persamaan regresi sederhana dapat dituliskan sebagai berikut :

$$
\begin{array}{ll} 
& \mathrm{Y}=\mathrm{a}+\mathrm{bX} \\
& \mathrm{Y}=18,552+0,203 \mathrm{X} \\
\text { Dimana: } & \mathrm{Y} \quad=\text { Kinerja Karyawan } \\
& \mathrm{a} \quad=\text { Koefisien Konstanta } \\
\mathrm{X} \quad=\text { Budaya Organisasi }
\end{array}
$$

Koefisien regresi (b) menyatakan perubahan rata-rata variabel $\mathrm{Y}$ untuk setiap perubahan variabel $X$. Perubahan ini merubahan peningkatan bila hasilnya positif dan penurunan bila hasilnya negatif. Maka hasil regresi tersebut menunjukkan bahwa variabel Budaya Organisasi (X) secara linier mempunyai pengaruh terhadap Kinerja Karyawan(Y) sebesar 0,203, yang artinya semakin bagus Budaya Organisasi (X) maka Kinerja Karyawan (Y) akan mengalami peningkatan.

Pada tabel diatas dapat diketahui nilai Sig. 0,012 lebih kecil daripada 0,05, maka $\mathrm{H}_{0}$ ditolak dan $\mathrm{H}_{1}$ diterima, yang berarti menunjukan bahwa Terdapat Pengaruh antara Budaya Organisasi (X) terhadap Kinerja Karyawan(Y).

\subsection{Uji regresi parsial (uji t)}

Uji t digunakan untuk mengetahui ada atau tidaknya pengaruh signifikan antara variabel Budaya Organisasi terhadap variabel Kinerja Karyawan secara parsial.

Pasangan Hipotesis :

$\mathrm{H}_{0}: \beta_{1}=0$, Tidak ada pengaruh positif antara Budaya Organisasi dengan Kinerja Karyawan

$\mathrm{H}_{1}: \beta_{1}>0$, Ada pengaruh positif antara Budaya Organisasi dengan Kinerja Karyawan

Dasar Pengambilan Keputusan:

- Berdasarkan tabel $\mathrm{t} \rightarrow$ nilai tabel $\mathrm{t}=v ; \alpha=(40-2) ; 0,05=2,024$ Jika nilai thitung lebih besar dari 2,024 maka $\mathrm{H} 0$ ditolak 
Jika nilai thitung kurang dari 2,024 maka $\mathrm{H} 0$ diterima

- Berdasarkan nilai signifikansi

Jika nilai signifikansi kurang dari 0,05 maka H0 ditolak

Jika nilai signifikansi lebih dari 0,05 maka $\mathrm{H} 0$ diterima

Tabel 10

Hasil Uji t

Coefficients $^{\mathrm{a}}$

\begin{tabular}{|c|c|c|c|c|c|c|}
\hline \multicolumn{7}{|c|}{ Coefficients $^{\mathrm{a}}$} \\
\hline \multirow[b]{2}{*}{ Model } & & Unstandardizec & Coefficients & $\begin{array}{l}\text { Standardized } \\
\text { Coefficients }\end{array}$ & & \\
\hline & & $\mathrm{B}$ & Std. Error & Beta & $\mathrm{t}$ & Sig. \\
\hline 1 & (Constant) & 18,552 & 4,581 & & 4,049 & 000 \\
\hline & Budaya Organisasi & ,203 &, 077 & 395 & 2,649 &, 012 \\
\hline
\end{tabular}

a. Dependent Variable: Kinerja Karyawan

Berdasarkan tabel coefficienst, nilai thitung adalah sebesar 2,649 dan nilai signifikansi sebesar 0,012. Dari hasil tersebut maka dapat disimpulkan bahwa nilai $t_{\text {hitung }}$ lebih besar dari $t_{\text {tabel }} 2,024$ maka $\mathrm{H}_{0}$ ditolak. Dengan kata lain "Terdapat hubungan positif antara Budaya Organisasi (X) dengan Kinerja Karyawan(Y)".

\subsection{Koefisien determinasi}

\section{Tabel 11}

Nilai Koefisien Determinasi Budaya Organisasi (X) Terhadap Kinerja

Karyawan (Y)

Model Summary

\begin{tabular}{lcccc}
\hline Model & $\mathrm{R}$ & $\mathrm{R}$ Square & $\begin{array}{c}\text { Adjusted R } \\
\text { Square }\end{array}$ & $\begin{array}{c}\text { Std. Error of the } \\
\text { Estimate }\end{array}$ \\
\hline 1 &, $395^{\mathrm{a}}$ &, 156 &, 134 & 4,83594 \\
\hline a. Predictors: (Constant), Budaya Organisasi \\
b. Dependent Variable: Kinerja Karyawan
\end{tabular}

Pada tabel Model Summary menjelaskan bahwa hasil yang di peroleh yaitu nilai $\mathrm{R}$ atau nilai kolerasinya sebesar 0,395 , nilai tersebut menunjukan bahwa hubungan kedua variabel adalah Rendah dan diperoleh nilai R Square atau koefisien Determinasi (KD) yang menunjukkan besarnya pengaruh variabel bebas dan variabel terikat. Nilai $\mathrm{R}^{2}$ yang diperoleh adalah 0,156 atau $15,6 \%$, sehingga dapat disimpulkan bahwa variabel bebas $\mathrm{X}$ memiliki pengaruh sebesar $15,6 \%$ terhadap variabel Y.

\section{B. Pembahasan Hasil}

1. Pengaruh variabel budaya organisasi $(x)$ terhadap kinerja karyawan $(y)$ secara parsial

Penelitian ini menunjukan bahwa Budaya Organisasi mempunyai pengaruh positif terhadap Kinerja Karyawan PT XYZ. Hasil uji t antara variabel Budaya Organisasi dengan Kinerja Karyawan menunjukkan siginifikan t sebesar 2,649 dengan probabilitas $(0,012)<\alpha=0,05$. Hasil tersebut memenuhi ketentuan uji pengaruh variabel secara parsial.

Hasil perhitungan dalam penelitian ini mendapatkan Nilai probabilitas < $\alpha=0,05$ maka H0 ditolak. Artinya bahwa variabel bebas berpengaruh secara parsial terhadap variabel terikat. Maka dari penelitian ini menunjukkan bahwa variabel Budaya Organisasi (X) sebagai variabel bebas secara parsial 
berpengaruh signifikan terhadap variabel Kinerja Karyawan (Y) sebagai variabel terikat pada karyawan PT XYZ.

Dari penelitian mempunyai pengaruh dengan nilai $R$ atau nilai kolerasinya yang menunjukan tingkat keeratan hubungan sebesar 0,395 atau $39,5 \%$, nilai tersebut menunjukan bahwa hubungan kedua variabel adalah rendah dan diperoleh nilai $\mathrm{R}$ Square atau koefisien Determinasi (KD) yang menunjukkan besarnya pengaruh variabel bebas dan variabel terikat. Nilai R2 yang diperoleh adalah 0,156 atau $15,6 \%$. Hasil tersebut memenuhi ketentuan uji pengaruh variabel secara Korelasi.

Berdasarkan hasil perhitungan dalam penelitian ini mendapatkan nilai $\mathrm{R}$ atau nilai kolerasinya sebesar 0,395 atau $39,5 \%$ dan nilai $\mathrm{R} 2$ yang diperoleh adalah 0,156 atau $15,6 \%$. Artinya bahwa variabel bebas berpengaruh sebesar $15,6 \%$ terhadap variabel terikat dengan tingkat keeratan 39,5\%. Maka dari penelitian ini menunjukkan bahwa variabel Budaya Organisasi (X) sebagai variabel bebas memiliki pengaruh sebesar 15,6\% dengan tingkat keeratan 39,5\% terhadap variabel Kinerja Karyawan (Y) sebagai variabel terikat pada karyawan PT XYZ.

\section{Kesimpulan}

Berdasarkan hasil penelitian yang dilakukan penliti mengenai pengaruh Budaya Organisasi (X) terhadap Kinerja Karyawan (Y) pada karyawan PT XYZ, maka diperoleh beberapa kesimpulan yaitu Hasil dari Analisis deskriptif mendapatkan kesimpulan bahwa seluruh indikator Budaya Organisasi (X) dan Kinerja Karyawan (Y) memperoleh setuju dan sangat setuju terhadap indikator yang digunakan, Hasil penelitian menunjukan bahwa Budaya Organisasi memiliki pengaruh positif terhadap Kinerja Karyawan denga tingkat keeratan hubungan 39.5\% dan Budaya Organisasi memiliki pengaruh sebesar 15,6\% terhadap Kinerja Karyawan. 


\section{BIBLIOGRAFI}

Amanda, Enno Aldea, Budiwibowo, Satrijo, \& Amah, Nik. (2017). Pengaruh budaya organisasi terhadap kinerja karyawan di PDAM Tirta Taman Sari Kota Madiun. Assets: Jurnal Akuntansi Dan Pendidikan, 6(1), 1-12. Google Scholar

Anwar Prabu, Mangkunegara. (2012). Manajemen Sumber Daya Manusia. Bandung: PT. Remaja Rosdakarya. Google Scholar

Badeni. (2013). Kepemimpinan dan Budaya Organisasi. Bandung: Alfabeta. Google Scholar

Edison, Emron, Anwar, Yohny, \& Komariyah, Imas. (2016). Manajemen sumber daya manusia. Bandung: Alfabeta. Google Scholar

Erni, Rernawan. (2011). Organization culture, budaya organisasi dalam perspektif ekonomi dan bisnis. Bandung: Alfabeta. Google Scholar

Novziransyah, Nanda. (2017). Pengaruh budaya organisasi terhadap kinerja karyawan PT. PLN (Persero) Kantor wilayah Sumatera Utara Medan. JUMANTIK (Jurnal Ilmiah Penelitian Kesehatan), 2(1), 14-25. Google Scholar

Robbins. (2015). Perilaku Organisasi (Organizational Behavior). Edisi 16. Fisipol UGM. Google Scholar

Sedarmayanti. (2017). Manajemen Sumber Daya Manusia. Academia. Google Scholar

Sudarmanto. (2014). Kinerja dan Pengembangan Kompetensi SDM. Yogyakarta: Pustaka Pelajar. Google Scholar

Sugiyono. (2017). Metode Penelitian Kuantitatif, Kualitatif, dan R\&D. Jakarta: Alfaberta. Google Scholar

Sutarto. (2015). Dasar-dasar Organisasi. Yogyakarta: Gadjah Mada University Press. Google Scholar

Torang, Syamsir. (2013). Organisasi \& manajemen; perilaku, struktur, budaya \& perubahan organisasi. Google Scholar

Wardani, Rodiathul Kusuma, Mukzam, M. Djudi, \& Mayowan, Yuniadi. (2016). Pengaruh Budaya Organisasi Terhadap Kinerja Karyawan (Studi Pada Karyawan PT Karya Indah Buana Surabaya). Jurnal Administrasi Bisnis, 31(1), 58-65. Google Scholar

Wilson, Bangun. (2012). Manajemen Sumber Daya Manusia. Jakarta: Penerbit Erlangga. Google Scholar

Wirawan, Agus. (2015). Evaluasi Kinerja Sumber Daya Manusia. Teori Aplikasi Dan 
Fitriana Dewi S, Astri Nur Rahmawati, Refani Khoirunnissa dan Ibnu Husni Fuadi

Penelitian, Jakarta: Salemba Empat. Google Scholar

\section{Copyright holder:}

Fitriana Dewi S, Astri Nur Rahmawati, Refani Khoirunnissa dan Ibnu Husni Fuadi (2021)

First publication right:

Journal Syntax Literate

This article is licensed under:
(c) $(\mathrm{C})$ 